\title{
TRANSTORNO DO ESPECTRO AUTISTA: FUNCIONAMENTO CEREBRAL E O IMPACTO DO DIAGNÓSTICO PARA PAIS E CUIDADORES
}

\section{ARTIGO DE REVISÃO}

COSTA, Dayana Cruz ${ }^{1}$

COSTA, Dayana Cruz. Transtorno do espectro autista: Funcionamento cerebral e o impacto do diagnóstico para pais e cuidadores. Revista Científica Multidisciplinar Núcleo do Conhecimento. Ano 05, Ed. 06, Vol. 01, pp. 65-75. Junho de 2020. ISSN: 2448-0959, Link de acesso: https://www.nucleodoconhecimento.com.br/psicologia/funcionamentocerebral

\section{RESUMO}

A Organização Mundial de Saúde (OMS) estima que, mundialmente, uma a cada 160 crianças sejam afetadas pelo Transtorno do Espectro Autista (TEA). Essa situação vem gerando muitos estudos e pesquisas acerca deste tema cujo propósito é compreender sua origem, avaliar suas necessidades e propiciar as melhores condições de desenvolvimento. Por essa razão, utilizando uma metodologia de pesquisa bibliográfica, o objetivo desta pesquisa é apontar as principais características e teorias em relação ao TEA e como o diagnóstico é recebido no âmbito familiar, pois entre o diagnóstico e a criança que o recebe está a família, que se vê em uma situação completamente nova e que, juntamente com a criança, precisa de apoio e orientação. Através do resultado obtido, pode-se constatar que as condições mais comuns nesse transtorno se apresentam nos primeiros anos de vida do indivíduo, caracterizados geralmente por uma dificuldade no desenvolvimento nas

${ }^{1}$ Graduação em Psicologia pelo Centro Universitário Celso Lisboa, Pós-graduação em Terapia Cognitivo-Comportamental pelo Centro Universitário Celso Lisboa e em Neuropsicologia pela Faculdade Venda Nova do Imigrante. 
áreas de comunicação e interação social, sendo a família a primeira a perceber os primeiros sinais de comportamentos atípicos na criança. Notou-se que a mãe é a figura familiar que mais sente o impacto do diagnóstico e a que mais apresenta riscos de desenvolver transtornos de ansiedade ou depressivo. Pode-se concluir que ainda não é possível apontar uma causa unânime para esse transtorno, porém a corrente mais aceita atualmente é a da área neurológica, segundo a qual é necessário entender as variações ocorridas na atividade do cérebro autista, como esse conhecimento pode ajudar em novas estratégias de manejo para esses pacientes, assim como a importância do acompanhamento psicológico aos pais e cuidadores que passam a ter uma nova rotina e desdobramentos dentro do ambiente familiar e diante da sociedade que ainda carece de conhecimento acerca de transtornos mentais.

Palavras-Chave: Transtorno do espectro autista, neurológica, família.

\section{INTRODUÇÃO}

Este tema vem sendo alvo de estudos e pesquisas por muitos anos, porém, devido a sua complexidade, ainda não é possível apontar uma causa unânime do Transtorno do Espectro Autista (TEA), contudo a corrente mais aceita atualmente é a da área neurológica que estuda o funcionamento cerebral (GARCIA; MOSQUERA, 2011).

Mundialmente, estima-se que uma em cada 160 crianças possui o TEA (JÚNIOR, 2017). No Brasil, calcula-se que esse número possa chegar a 2 milhões de autistas (OLIVEIRA, 2019). Esses dados tornam importante uma análise das principais características do TEA, as implicações no cérebro desses indivíduos e uma discussão sobre o impacto desse diagnóstico no ambiente familiar.

Os pais são os primeiros a notar déficits no comportamento da criança e a partir daí se inicia uma jornada rumo ao diagnóstico.

Os primeiros sintomas podem se manifestar durante o segundo ano de vida da criança, contudo se os sintomas forem graves podem ser observados antes dos dois anos de idade. Geralmente os primeiros sinais se mostram através de uma dificuldade 
no desenvolvimento da linguagem e na interação social, mas também pode ocorrer a perda de habilidades já desenvolvidas (APA, 2014).

Diante da indicação do diagnóstico de TEA, pais e cuidadores têm reações diferentes, alguns acham que não vão conseguir lidar com essa criança, outros já aceitam mais facilmente, enquanto há aqueles que se surpreendem ao longo do processo supondo que reagiriam de uma forma, mas ao receber o diagnóstico agem diferente, seja positivamente ou negativamente.

Portanto, esse artigo tem o objetivo de apresentar de forma clara os sinais iniciais que podem direcionar para um diagnóstico, mostrar os aspectos neurológicos e como os pais e cuidadores recebem esse diagnóstico.

Além do acolhimento das crianças com o diagnóstico ou suspeita de TEA que chegam ao consultório psicológico para o processo terapêutico, é preciso receber os pais e cuidadores que muitas vezes chegam "sem chão" e com muitas dúvidas. Neste artigo foi utilizada como metodologia a pesquisa bibliográfica, que possui um vasto material que aborda o assunto através de autores dos quais se destacam Silva; Gaiato; Reveles (2012), Garcia; Mosquera (2011) e Gallo-Penna (2006).

\section{TRANSTORNO DO ESPECTRO AUTISTA}

No DSM-IV, o então transtorno autista fazia parte de um grupo denominado de Transtornos globais do desenvolvimento que integrava, dentre outros, o Transtorno de Asperger e o Transtorno de Rett. A partir do DSM-V houve uma reorganização da definição de autismo e de seus critérios diagnósticos o qual passou a integrar o grupo dos transtornos do neurodesenvolvimento. Essa reorganização resultou, ainda, na alteração do seu nome para Transtorno do Espectro Autista (TEA) (BARNHILL, 2015).

Nos transtornos do neurodesenvolvimento, os sinais começam a aparecer nos primeiros anos de vida, nos quais já se podem notar algumas variações no comportamento da criança e que podem causar déficits ao longo da vida do indivíduo (APA, 2014). 
O transtorno do espectro autista, como explica o DSM-V, caracteriza-se por déficits, de caráter contínuo, na comunicação e na interação social, bem como na existência de padrões repetitivos e restritos de interesses, comportamentos e atividades (APA, 2014).

Logo na primeira infância é possível notar alguns sinais de alteração no comportamento da criança como: dificuldade de interação, tendência ao isolamento e apego a objetos aparentemente sem valor, atraso na linguagem, interesse por enfileirar objetos ou brinquedos, sensibilidade a barulhos, dificuldade de mudar a rotina, entre outros.

Algumas crianças apresentam um desenvolvimento típico e, de repente, começam a regredir, param de falar e interagir. Em outros casos, sempre apresentaram dificuldades no desenvolvimento das áreas de comunicação e interação social. (APA, 2014).

Observar esses tipos de déficits no comportamento desde cedo pode ajudar em um diagnóstico precoce, potencializando o tratamento e resultados.

Outros autores também atribuem como características desse transtorno os comportamentos repetitivos e estereotipados e a fixação em um tema específico (GARCIA; MOSQUERA, 2011).

No diagnóstico do transtorno do espectro autista, as características clínicas individuais são registradas por meio do uso de especificadores (com ou sem comprometimento intelectual concomitante; com ou sem comprometimento da linguagem concomitante; associado a alguma condição médica ou genética conhecida ou a fator ambiental), bem como especificadores que descrevem os sintomas autistas (idade da primeira preocupação; com ou sem perda de habilidades estabelecidas; gravidade). Tais especificadores oportunizam aos clínicos a individualização do diagnóstico e a comunicação de uma descrição clínica mais rica dos indivíduos afetados. Por exemplo, muitos indivíduos 
anteriormente diagnosticados com transtorno de Asperger atualmente receberiam um diagnóstico de transtorno do espectro autista sem comprometimento linguístico ou intelectual. (APA, 2014, p.32).

O nível do autismo passou a ser mensurado por esses especificadores de gravidade, que sinalizam o nível de comprometimento que o indivíduo apresenta. Sendo: nível 03 (exigindo muito apoio); nível 02 (exigindo apoio substancial) e nível 01 (exigindo apoio) (NEUMANN et al., 2016).

A utilização desses especificadores para fim de diagnóstico nos transtornos do neurodesenvolvimento ajuda para que se possa acompanhar e analisar o curso clínico do indivíduo (APA, 2014).

\section{FUNCIONAMENTO CEREBRAL NO TEA}

Este tema vem sendo alvo de estudos e pesquisas por muitos anos, porém, devido a sua complexidade, ainda não é possível apontar de forma universal uma causa para - TEA. Entretanto, a corrente mais aceita atualmente é a da área neurológica, segundo a qual as mutações genéticas e os sintomas ocorrem por falhas na comunicação entre regiões do cérebro (GARCIA; MOSQUERA, 2011).

Entender as modificações que ocorrem no cérebro do indivíduo com TEA é importante para que se possam formular estratégias que auxiliem no desenvolvimento de habilidades sociais mais satisfatórias. (ZILBOVICIUS; MERESSE; BODDAERT, 2006).

Quando analisamos o funcionamento do indivíduo com TEA, percebemos que eles apresentam déficits em diversas áreas e não apenas em uma específica, por esse motivo não podemos apontar só uma área cerebral que seja a causa (SILVA; GAIATO; REVELES, 2012).

Nos últimos anos, pesquisas têm apontado para algumas estruturas cerebrais que têm sofrido alterações no TEA, que são: o sistema límbico: responsável pelas emoções; o corpo caloso: estrutura que conecta o lado direito com o esquerdo do cérebro; os 
gânglios da base: responsáveis pelo controle motor, cognição, emoção e aprendizado; o tálamo: área envolvida com a regulação do estado de consciência, alerta, controle das emoções e atenção; o cerebelo: encarregado do comando do tônus muscular, da manutenção do equilíbrio, movimentos voluntários e de toda aprendizagem que envolve movimentos, como andar, correr e pular; a substância branca: responsável pela comunicação entre as partes do cérebro; a região frontotemporal: responsável pela interação social e pela linguagem. Uma região que também apresenta destaque nas pesquisas de neuroimagem e estudos sobre as bases do TEA é a amígdala, relativa à emoção e socialização (GARCIA; MOSQUERA, 2011).

Alguns estudos mostraram que a noradrenalina, dopamina e serotonina, neurotransmissores que são encarregados pela propagação de informações e aprendizados, estariam com seu funcionamento comprometido. Fazendo com que o cérebro não funcione de forma congruente. Outra variação observada diz respeito ao tamanho do cérebro, pois existiria uma propensão a cérebros mais volumosos em indivíduos com TEA (SILVA; GAIATO; REVELES, 2012).

Estudos realizados com ressonância magnética funcional apontam para uma dificuldade da ativação cerebral da área de identificação de leituras de face, o giro fusiforme. Durante a observação de distintas expressões faciais, essa área não fica tão ativa no cérebro do indivíduo com TEA (SILVA; GAIATO; REVELES, 2012).

Segundo Williams (2001 apud GARCIA; MOSQUERA, 2011), o estudo dos neurônios espelhos (NE) também tem ganhado espaço nas pesquisas para a compreensão do TEA. Uma falha no desenvolvimento do sistema desses neurônios poderia causar déficits na sua formação, contribuindo para a evolução do transtorno.

Estudos de imagem funcional em seres humanos também demonstram o funcionamento do espelhamento. Por exemplo, uma pessoa que abana a mão para dizer "tchau" apresenta atividade cerebral na região do córtex motor semelhante a uma pessoa que estiver apenas observando esse aceno. Outros estudos mostraram ainda atividade nos 
neurônios-espelho quando fazemos ou observamos caretas. (SILVA; GAIATO; REVELES, 2012, p.183).

O sujeito com TEA apresenta um decréscimo na ativação dos NE, o que faz com que eles percebam menos as atitudes das outras pessoas (SILVA; GAIATO; REVELES, 2012).

De acordo com Jurado e Rosselli (2007 apud CZERMAINSKI; BOSA; SALLES, 2013), outra vertente que também é apontada nos estudos do TEA é a análise das funções executivas. As funções executivas são processos cognitivos complexos que usamos o tempo todo. Através dessas funções, nós traçamos estratégias, pensamos em resoluções de problemas, planejamos, usamos nossa memória de trabalho e flexibilidade cerebral. Portanto, são funções que usamos constantemente em nosso dia a dia e nem nos damos conta, mas para o indivíduo com TEA não é algo tão simples.

Os déficits nessas funções estão relacionados ao lobo frontal que é responsável pela organização de informações, planejamento e execução de atividades. Os indivíduos com TEA têm dificuldade, justamente, no planejamento de tarefas, no controle de suas ações, bem como em encontrar estratégias diferentes para resolver problemas. Em vez disso, permanecem com os mesmos recursos ainda que eles não estejam funcionando (SILVA; GAIATO; REVELES, 2012).

\section{IMPACTO DO DIAGNÓSTICO NO AMBIENTE FAMILIAR}

Temos percebido ao longo dos anos um acréscimo do número de casos de TEA. Considerando informações do CDC (Center of Deseases Control and Prevention), o qual possui vínculo com o governo dos Estados Unidos, hoje, a cada 110 pessoas, temos um caso de autismo. Calcula-se que no Brasil o número se aproxime de 2 milhões de autistas (OLIVEIRA, 2019).

Desde o momento que os pais têm conhecimento da chegada de um filho, criam milhares de expectativas e sonhos, conforme a criança vai crescendo e se 
desenvolvendo podem perceber algumas limitações, comportamentos inadequados ou não condizentes com a faixa etária da criança, então começa uma desconfiança e uma trajetória para descobrir o motivo de tais comportamentos (FILHO et al., 2016).

Além do acolhimento das crianças com o diagnóstico ou suspeita de TEA que chegam ao consultório psicológico para o processo terapêutico, é preciso receber os pais e cuidadores que muitas vezes chegam "sem chão" e com muitas dúvidas.

Quando a família recebe um diagnóstico de TEA, passa por um processo de rejeição e aceitação, tudo fica confuso e enfrentam sentimentos conflitantes (GALLO-PENNA, 2006).

Depois do diagnóstico a família passa por um período de reorganização. Pode ser um período muito estressante, pois são necessárias que decisões importantes sejam tomadas, como tipos de tratamentos, terapias e delineamento do papel que cada membro da família terá frente a essa nova realidade (SANCHEZ; BAPTISTA, 2009).

Diante de um diagnóstico de TEA, pais e cuidadores têm reações diferentes, alguns acham que não vão conseguir lidar com essa criança, outros já aceitam mais facilmente e tem aqueles que se surpreendem ao longo do processo, achando que reagiriam de uma forma, mas ao receber o diagnóstico agem diferente, seja positivamente ou negativamente.

Diante de algo novo e muitas vezes com pouca informação sobre o transtorno, alguns pais acabam se retraindo e absorvendo as dificuldades do dia a dia sozinhos. Por vezes, têm medo de expor seus filhos com receio dos olhares e julgamentos da sociedade (ONZI; GOMES, 2015).

Os pais que recebem o diagnóstico de TEA de forma negativa podem desenvolver transtornos de humor, como a depressão, transtornos de ansiedade, estresse e problemas de saúde (SANCHEZ; BAPTISTA, 2009).

Muitos pais acabam tendo que renunciar a sua vida pessoal para se dedicar a essa criança e em algum momento essa renúncia pode gerar conflitos com eles mesmos. 
Frequentemente nas famílias, quem assume os cuidados do filho é a mãe. É ela quem, muitas vezes, tem que abrir mão até mesmo de uma carreira profissional para se dedicar a essa criança (GALLO-PENNA, 2006).

A mãe é a principal cuidadora dos portadores de Autismo e, por isso, está mais propensa ao desenvolvimento de altos níveis de estresse, o que resulta em sobrecarga e agravos na saúde física e psicológica das mães. Outros fatores que podem contribuir para o surgimento da sobrecarga são: a falta de apoio conjugal, o excesso de cuidados com o filho, o isolamento social e a escassez de apoio social. (SCHMIDT; BOSA, 2007 apud FILHO et al., 2016).

Ainda hoje a sociedade acaba colocando a responsabilidade do cuidado do filho com transtorno sobre a mãe, muito mais que sobre o pai. Pesquisas mostram que as mães estão mais suscetíveis a crises de estresse. Algumas se sentem desamparadas pelos maridos e gostariam que eles expressassem vontade de compartilhar os cuidados com o filho (SCHMIDT; BOSA, 2003).

Os pais e cuidadores também precisam lidar com os preconceitos da sociedade, pois uma criança com TEA muitas vezes não exibe um comportamento convencional, o que pode ocasionar olhares de reprovação das pessoas à volta, seja em um shopping, em uma fila de banco ou no supermercado. Além da pressão e da cobrança de si mesmos para tentar fazer o melhor pelos seus filhos, ainda tem que encarar a pressão de uma sociedade ainda desinformada sobre transtornos mentais em geral.

O papel da família é primordial na vida do indivíduo com TEA, depois do processo de aceitação do diagnóstico buscam conhecer o transtorno e saber sobre as melhores maneiras de ajudar no desenvolvimento. (FILHO et al., 2016).

Quando os pais reconhecem e aceitam as necessidades do seu filho, esquecem o medo de julgamentos e preconceitos e buscam oferecer uma melhor qualidade de vida para ele, oferecem para essa criança o que de melhor ela poderia receber (ONZI; GOMES, 2015). 
Fica clara a necessidade de uma rede de apoio também aos pais e cuidadores, pois ao entrar em um mundo totalmente novo para alguns deles é fundamental que recebam o suporte e as informações corretas sobre o TEA.

Quem cuida merece cuidados tanto quanto quem é cuidado (SANCHEZ; BAPTISTA, 2009).

\section{CONSIDERAÇÕES FINAIS}

As estimativas do número de casos de TEA, mundialmente e no Brasil, colaboraram para a produção de pesquisas e teorias sobre o assunto, contudo a mais aceita atualmente é a da área neurológica. De acordo com essa área, as mutações genéticas e os sintomas ocorrem por falhas na comunicação entre regiões do cérebro. $O$ estudo e a compreensão do funcionamento cerebral em autistas têm sido de suma importância para identificar e estimular áreas cerebrais afetadas e promover um melhor desenvolvimento desses indivíduos.

Na primeira infância já podemos perceber os sinais iniciais do TEA, por isso os pais normalmente são os primeiros a identificar os sintomas nos seus filhos. Então se inicia a busca de um diagnóstico que geralmente é recebido com frustração pelos pais e cuidadores.

Pesquisas mostram que a mãe é o membro da família que mais se dedica ao filho com transtorno e a mais propensa a desenvolver crises de ansiedade ou outros distúrbios.

A revisão literária apontou que os familiares de pessoas com TEA precisam receber cuidado e ter uma rede de apoio tanto quanto seus filhos, pois ainda vivemos em uma sociedade onde os portadores de transtornos são vistos de forma preconceituosa e, por vezes, depreciativa. Dessa forma, é a família quem absorve esses olhares distorcidos de uma parcela da população ainda sem informação. 


\section{REFERÊNCIAS}

AMERICAN PSYCHIATRY ASSOCIATION (APA). Manual Diagnóstico e Estatístico de Transtornos Mentais- DSM-V. Porto Alegre, Artmed. 2014.

BARNHILL, John Warren. Casos Clínicos do DSM-5. Porto Alegre, Artmed. 2015.

CZERMAINSKI, Fernanda Rasch; BOSA, Cleonice Alves; SALLES, Jerusa Fumagalli de. Funções Executivas em Crianças e Adolescentes com Transtorno do Espectro do Autismo: Uma Revisão, Porto Alegre, out/nov. 2013. Psico. Disponível em: < https://www.lume.ufrgs.br/bitstream/handle/10183/159391/001015688.pdf?sequence $=1$ \&isAllowed $=\mathrm{y}>$. Acesso em: 23 ago. 2019.

FILHO, Antônio Luiz Martins Maia et al. A importância da família no cuidado da criança autista, Teresina, jan/jun. 2016. Revista saúde em foco. Disponível em: <http://www4.fsanet.com.br/revista/index.php/saudeemfoco/article/viewFile/719/1000 >. Acesso em: 16 ago. 2019.

GALLO-PENNA, Eliana Cristina. Qualidade de Vida de Mães de pessoas com o diagnóstico de Autismo, São Paulo, 2006. Cadernos de pós-graduação em distúrbios

do

desenvolvimento.

Disponível

em:

<http://editorarevistas.mackenzie.br/index.php/cpgdd/article/view/11156/6887>.

Acesso em: 20 ago. 2019.

GARCIA, Priscila Mertens; MOSQUERA, Carlos Fernando França. Causas Neurológicas Do Autismo, Paraná, jan/jun. 2011. O Mosaico. Disponível em: http://periodicos.unespar.edu.br/index.php/mosaico/article/viewFile/19/pdf. Acesso em: 22 ago. 2019.

JÚNIOR, Edgard. OMS afirma que autismo afeta uma em cada 160 crianças no mundo. ONU News, 2017. Disponível em : $<$ https://news.un.org/pt/story/2017/04/1581881-oms-afirma-que-autismo-afeta-umaem-cada-160-criancas-no-mundo >. Acesso em: 13 maio de 2020. 
NEUMANN, Débora Martins Consteila et al. Avaliação Neuropsicológica Do Transtorno Do Espectro Autista, Guaíba, jun. 2016. Psicologia.PT. Disponível em: <http://www.psicologia.pt/artigos/textos/A1087.pdf>.Acesso em 20 ago.2019.

OLIVEIRA, Carolina. Um Retrato Do Autismo No Brasil, São Paulo, mar. 2019. Revista espaço aberto. Disponível em: <http://www.usp.br/espacoaberto/?materia=umretrato-do-autismo-no-brasil>. Acesso em 27 ago. 2019.

ONZI, Franciele Zanella; GOMES, Roberta de Figueiredo. Transtorno Do Espectro Autista: A Importância Do Diagnóstico E Reabilitação, Porto Alegre, 2015. Caderno pedagógico.

Disponível

em: $<$ http://univates.br/revistas/index.php/cadped/article/view/979/967>. Acessado em 20 ago. 2019.

SANCHEZ, Fátima lara Abad; BAPTISTA, Makilim Nunes. Avaliação familiar, sintomatologia depressiva e eventos estressantes em mães de crianças autistas e assintomáticas. São Paulo, jun. 2009. Pepsic. Disponível em: $<$ http://pepsic.bvsalud.org/scielo.php?script=sci_arttext\&pid=S198334822009000100005>. Acesso em: 20 ago. 2019.

SCHMIDT, Carlos; BOSA, Cleonice. A investigação do impacto do autismo na família: Revisão crítica da literatura e proposta de um novo modelo. Paraná, 2003. Biblioteca digital de periódicos. Disponível em: <https://revistas.ufpr.br/psicologia/article/view/3229>. Acesso em: 20 ago.2019.

SILVA, Ana Beatriz Barbosa; GAIATO, Mayra Bonifacio; REVELES, Leandro Thadeu. Mundo Singular. Entendendo o autismo. Rio de Janeiro: Objetiva LTDA,2012.

ZILBOVICIUS, Mônica; MERESSE, Isabelle; BODDAERT, Nathalie. Autismo: neuroimagem. França, 2006. Revista Brasileira Psiquiatria. Disponível em: <http://www.scielo.br/pdf/rbp/v28s1/a04v28s1.pdf>. Acessado em: 23 ago. 2019.

Enviado: Abril, 2020. 
Aprovado: Maio, 2020. 